\title{
La carga económica global de la COVID-19: Cada día más lejos de la Agenda 2030 para el Desarrollo Sostenible
}

\author{
The global economic burden of COVID-19: Every day further from the 2030 Agenda for \\ Sustainable Development
}

\author{
Lorena A. Cervantes-Pérez', Gabino Cervantes-Pérez², Gabino Cervantes-Guevara²,3 y \\ Enrique Cervantes-Pérez $z^{3,45}$ \\ 'Unidad de Trasplante de Médula Ósea, Instituto Nacional de Cancerología, Ciudad de México; ${ }^{2}$ Departamento de Gastroenterología, Hospital Civil \\ de Guadalajara Fray Antonio Alcalde, Guadalajara, Jalisco; ${ }^{3}$ Departamento de Bienestar y Desarrollo Sustentable, Centro Universitario del Norte, \\ Universidad de Guadalajara, Colotlán, Jalisco; ${ }^{4}$ Departamento de Nutriología, Clínica Instituto Nacional de Ciencias Médicas y Nutrición Salvador \\ Zubirán, Ciudad de México; ${ }^{5}$ Departamento de Medicina Interna, Hospital Civil de Guadalajara Fray Antonio Alcalde, Guadalajara, Jalisco. México
}

\section{Al editor:}

Al igual que las guerras y los cambios sociopolíticos, las enfermedades contagiosas han cambiado la economía y la política del mundo a lo largo de la historia. En 2020, el mundo se enfrenta a la COVID-19, la enfermedad causada por el coronavirus 2 del síndrome respiratorio agudo severo (SARS-CoV-2), un virus que en todo el mundo ha provocado pérdidas masivas y pánico social y económico'. Etiquetado como un evento de cisne negro y comparado con el escenario económico de la Segunda Guerra Mundial, la pandemia de COVID-19 ha tenido un impacto negativo en los sistemas de salud del mundo con un efecto dominó en cada aspecto de la vida humana tal como la conocemos $^{2}$. El impacto de la COVID-19 sobre las desigualdades en salud no solo se producirá en términos de infección y mortalidad por el virus, sino también en términos de las consecuencias para la salud por las respuestas a las políticas emprendidas en la mayoría de los países ${ }^{3}$.

La pandemia de COVID-19 y los esfuerzos de distanciamiento social implementados para frenar su propagación han perturbado las economías y los sistemas alimentarios mundiales y locales. La inseguridad alimentaria sigue de cerca las condiciones económicas nacionales y de los hogares, con tendencias paralelas al desempleo, la pobreza y los precios de los alimentos. La COVID-19 amenaza el acceso a los alimentos por sus efectos en los costos de estos y en la infraestructura, incluidos los cambios en la distribución de la asistencia alimentaria, el acceso al transporte público y la escasez de ciertos productos. En términos de utilización, los informes de mercado indican cambios generalizados en los comportamientos de la compra de alimentos ${ }^{4}$. El impacto súbito y generalizado de la pandemia y las medidas de suspensión de las actividades que se adoptaron para contenerla han ocasionado una drástica contracción de la economía mundial. Según las previsiones del Banco Mundial, la economía crecerá un 4\% en 2021 después de una contracción del 4,3\% el año pasado, la cuarta recesión mundial más profunda en los últimos 150 años, solo superada por aquellas relacionadas con las dos guerras mundiales y la Gran Depresión. La recuperación de este año supone que las medidas de control reducirán las tasas de infección y que el proceso de vacunación se acelerará para que la cobertura sea generalizada en todo el mundo hacia fines del próximo año. Se espera que la producción en las economías de mercados emergentes y en desarrollo crezca un 5\% este año,

\section{Correspondencia:}

*Enrique Cervantes-Pérez

Vasco de Quiroga 15

Col. Belisario Domínguez, Sección XVI, Del. Tlalpan

C.P. 14080 , Ciudad de México, México

Fecha de recepción: 26-12-2020

Fecha de aceptación: 11-01-2021

E-mail: enrique.cervantes@academico.udg.mx

0009-7411/@ 2021 Academia Mexicana de Cirugia

(http://creativecommons.org/licenses/by-nc-nd/4.0/).
Cir Cir. 2021;89(3):418-419

Contents available at PubMed www.cirugiaycirujanos.com ajo la licencia CC BY-NC-ND 
pero esto tras los impactos económicos que echaron por tierra al menos 10 años de crecimiento del ingreso per cápita en más de una cuarta parte de los países de este grupo 5 .

Los Objetivos de Desarrollo Sostenible constituyen un llamamiento universal a la acción para poner fin a la pobreza, proteger el planeta y mejorar las vidas y las perspectivas de las personas en todo el mundo. En 2015, la Asamblea General de las Naciones Unidas aprobó 17 objetivos como parte de la Agenda 2030 para el Desarrollo Sostenible, en la cual se establece un plan para alcanzar los objetivos en 15 años. La Agenda 2030 es una oportunidad histórica para conseguir un mundo más inclusivo, justo y sostenible. Sin embargo, la crisis de la pandemia de COVID-19 supone un punto de inflexión para la consecución de los Objetivos de Desarrollo Sostenible, por sus demoledoras consecuencias en el plano político, económico y sociocultural en pleno siglo XXI. El optimismo y las esperanzas que generó la elaboración de la Agenda 2030 han dado paso, en el contexto de la pandemia global, a una creciente preocupación por una posible desaceleración en la consecución de sus objetivos o incluso un grave retroceso de los logros ya alcanzados.

\section{Agradecimientos}

Los autores agradecen al Departamento de Nutriología Clínica del Instituto Nacional de Ciencias Médicas y Nutrición Salvador Zubirán.

\section{Responsabilidades éticas}

Protección de personas y animales. Los autores declaran que para esta investigación no se han realizado experimentos en seres humanos ni en animales.

Confidencialidad de los datos. Los autores declaran que en este artículo no aparecen datos de pacientes.

Derecho a la privacidad y consentimiento informado. Los autores declaran que en este artículo no aparecen datos de pacientes.

\section{Conflicto de intereses}

El Dr. Enrique Cervantes Pérez es actualmente Entrenador Médico Científico en Laboratorios Janssen Cilag.

\section{Bibliografía}

1. Ceylan RF, Ozkan B, Mulazimogullari E. Historical evidence for economic effects of COVID-19. Eur J Health Econ. 2020;21:817-23.

2. Nicola M, Alsafi Z, Sohrabi C, Kerwan A, Al-Jabir A, losifidis C, et al. The socio-economic implications of the coronavirus pandemic (COVID-19): a review. Int J Surg. 2020;78:185-93.

3. Bambra C, Riordan R, Ford J, Matthews F. The COVID-19 pandemic and health inequalities. J Epidemiol Community Health. 2020;74:964-8.

4. Niles MT, Bertmann F, Belarmino EH, Wentworth T, Biehl E, Neff R. The early food insecurity impacts of COVID-19. Nutrients. 2020;12:E2096.

5. Global Economic Prospects, January 2021. Disponible en: https://www. worldbank.org/en/publication/global-economic-prospects. 